\title{
Accounting Offshoring: The role of Emotional Intelligence
}

\author{
Gaurav Gupta ${ }^{\mathrm{a}, 1}$, Stephen B. Salter ${ }^{\mathrm{b}}$ and Philip A. Lewis ${ }^{\mathrm{c}}$ \\ ${ }^{a}$ University of North Carolina Wilmington \\ ${ }^{\mathrm{b}}$ Middle Tennessee State University \\ ${ }^{\mathrm{c}}$ Eastern Michigan University
}

\begin{abstract}
Research Question: The primary purposes of this paper are to compare the emotional intelligence levels of Americans and Indians and explore the potential impacts of these differences in the offshoring relationships. Motivation: The continued growth of the Indian economy and its legions of inexpensive Englishspeaking graduates has made India a global leader in business process offshoring. U.S. companies, including accounting firms, routinely offshore a variety of their business functions to India. However, the effective functioning of these offshoring relationships has been offset by perceptions of the Indian providers' poor communication and ineffective management training (Downey, 2018; Jain, 2015; Mayur, James, and Swamynathan, 2015). We believe that a culture-influenced behavioral factor known as Emotional Intelligence (EI) has resulted in less than the optimal performance outcome for the U.S. public accounting firms in these offshoring relationships. Data: Using MSCEIT EI inventory, we collect data from 197 master's students enrolled in accounting courses in India and the U.S. on four branches of EI. Findings: Our results indicate that the Indian students have statistically lower levels of EI than the U.S. students. We discuss the implications for public accounting firms that offshore to India and advocate for the inclusion of the EI related coursework in Indian master's programs and firm training. Contribution: Using a well-established inventory of EI, our study provides a
\end{abstract}

${ }^{1}$ Corresponding author: Gaurav Gupta, Assistant Professor, Department of Accountancy and Business Law, Cameron School of Business, University of North Carolina Wilmington, 601 S College Rd, Wilmington, NC 28406, Phone: (910) 962-2798, guptag@uncw.edu 
deeper understanding of the cultural EI differences between Americans and Indians, and the possible implications for the offshoring environment.

Keywords: India, emotional intelligence, audit, culture, offshoring, Big 4 accounting firms.

\section{JEL codes: $M 41$}

\section{Introduction}

To an average accounting researcher or teacher, it is often not clear what the current trends and issues in accounting practice are. A simple Google search reveals many choices, from technology to demographics. This paper focuses on three widely cited issues: Emotional Intelligence (EI), national culture, and the offshoring relationship.

In this research, we collect data and compare participants' EI skills from two countries, the U.S. and India. We limit the paper to these countries because not only they are very different culturally, but are also locked into an offshoring relationship, where the U.S. firm serves as the internal client, and the Indian subsidiary of the firm serves as the provider of auditing and accounting services. These relationships are significant but can be difficult. Deloitte U.S.-India, which is a region of the U.S. practice and not a part of Deloitte India, employs 25 percent of the Deloitte U.S workforce (Shaikh, 2017). As Andiola et al. (2018: 3) observe "Offshore professionals comprise a critical resource for public accounting firms, due to the current shortage of skilled onshore accounting professionals and pressure to keep costs low." However, the effective functioning of these offshoring arrangements can be reduced by Indian providers' poor communication and ineffective management training (Downey, 2018; Jain, 2015; Mayur et al., 2015). We believe that the communication issue may be the most serious and reflects differences in Emotional Intelligence (EI) between the two countries.

So, what is EI? EI represents the ability to understand one's emotions and those of others. It also measures one's ability to control emotions and use them to communicate with others through appealing to their emotional needs while controlling one's own. Mayer, Salovey, and Caruso (2008) present this as a tool that improves the quality and speed of task completion. EI comes from the same group of base theories that describes all facets of human intelligence. El is one of the newest members of a class of intelligence including the social, practical, and personal intelligence that help individuals manage issues that are crucial to their ability to cope with their environment. These groups of intelligences not only help with survival but also help individuals progress their agenda (Zajonc, 1980). 
EI is of particular interest to accounting academics because it directly affects the ability to communicate and function in an audit scenario. From an international academic perspective, cross-national differences in EI have been largely neglected (see Huynh et al. (2018) for a summary). Further, in the context of an offshoring relationship where persons in one culture must understand and, in the end, sign off on the work of another, the understanding of the other is crucial. When people in different groups do not communicate with similar levels of EI, the two-way communication becomes less effective. These differences can lead to ineffective functioning and reduced cohesion in team environments (O'Boyle et al., 2011).

While Mayer and Salovey (1997) initially presented EI as a universal construct, there continues to be a considerable debate about the universality of EI levels in people from different cultures and backgrounds. In a recent literature review, Huynh et al. (2018) conclude that national culture may well influence EI but conclude that the data is still incomplete. Empirical studies at the national level have produced mixed results and with different cultural variables. Karim and Weisz (2010), for example, report that the levels of EI are higher in individualist France than communitarian Pakistan. Moon (2011) finds similar results for samples of Asian and Anglo students but adds power distance. Other studies, such as Tang et al. (2010) find no overall difference, or reverse the direction of the cultural dimension to EI (Gunkel et al., 2014). Hofstede et al. (2010) indicate that India continues to be a low individualism country, and the U.S. is the highest scoring country on the individualism scale. Based on the limited literature, we hypothesize that if EI is culture driven, we expect that Indians are more likely to be lower in EI and that is what we wish to test.

Using a sample of master's students in accounting courses, both in India and the U.S., and the MSCEIT instrument, we indeed find that India's current and future managers show lower levels of EI than their U.S. counterparts. Even after controlling for demographic variables, the explanatory power of cultural values continues to dominate. While this may not be a problem within India, it becomes a problem as the two cultures interact. As described in Downey (2018), this lower EI can explain communication and understanding problems between U.S. managers and Indian staff. For those U.S. firms proposing to offshore higher-level tasks, they may be put in a position of having to trade the price of labor against the level of emotional insight. As educators and academicians, the good news is that unlike other psychological issues such as narcissism, EI skills can be learned through training. This offers opportunities for firms and universities to rectify the problem (see Herpertz et al., 2016; Rodriguez et al., 2017).

This paper now continues with a literature review, hypotheses, methodology, and findings. We end with a discussion of the results and the possibility of training and other exercises to reduce the impact of intercultural differences. 


\section{Literature review}

\subsection{Offshoring and India}

Offshoring is the process of using unaffiliated foreign companies or affiliated subsidiaries to perform services primarily for the internal market. The advantages of offshoring include substantially lower wage and benefit costs, and labor consolidation as tasks are done repeatedly in the same location. There are also further scale benefits and increased service quality and costs by having fewer process exceptions. Also, firms can work around the clock by taking advantage of time zone differences between the national organization and the offshore provider. At a more theoretical level, Buckley and Ghauri (2004) present offshoring strategies as an effort by firms to disaggregate their value chains globally and to integrate the comparative advantages of geographic locations with the competitive advantages of company resources and competencies.

India is the global leader in Business Process Outsourcing (BPO) and offshoring (Ho et al., 2012; Deloitte, 2015). Kearney (2017) continues to rank India as the topmost global services location seeing off its nearest competitor China with its depth and breadth of English-speaking skilled labor. In 2016, the OECD (OECD, 2016) reported that India's net export of services stood at U.S. Dollars 65.7 billion, which is an increase of 72 percent from 2010. There is, however, caution in this OECD data as both 2015 and 2016 net service exports figures are below the peak of U.S. Dollars 76.5 billion in 2014.

Why this sudden growth and why the potential slowdown? First, cost and available qualified labor in India encourage growth in offshoring. Andiola et al. (2018: 3) observe "Offshore professionals comprise a critical resource for public accounting firms, due to the current shortage of skilled onshore accounting professionals and pressure to keep costs low."

Second is the ability to use the global time zone to actually achieve a 24-hour workday without the HR problems associated with U.S. domestic shift work. Downey (2018) conducts semi-structured interviews with a small sample of U.S auditors to understand the functioning and foibles of offshoring. Justifying offshoring, one respondent reported the following:

By having our resources overseas in India, it was kind of like having a 24-hour audit. That sounds terrible and overly efficient. We would kind of laugh at my partners when they would say that. But in a way, it was helpful, because we would go home at night and send something over there. Then, when we got back in the morning chances are, they'd have something, a finished product of some sort to send us or had made progress. (Downey, 2018: 215) 
Finally, the desire to hire and retain high EI staff in the U.S. by creating more emotionally satisfying work and seeking cost savings by offshoring are not unrelated. Andiola et al. $(2018,3)$ note that "Offshoring also is described as assisting firms in their efforts to meet the expectations of U.S. Millennials, who seek more interesting work and greater work-life balance." Therefore, offshoring can be seen as substituting an inexpensive form of labor to be able to afford the preferences of a desired and highly emotionally intelligent group.

Although offshoring is growing, it is not without problems. Research has provided evidence that offshoring may cause firms to incur additional costs because of the need to redesign the work of the home country staff (Farrell, 2005; Larsen et al. 2011). Firms also mention difficulty in coordinating cross-national/cross-cultural teams. For example, Downey (2018: 221), mentions one respondent's frustration with field work and completion issues from the Indian sub-contractors:

It seems that the Indian culture does not like to admit being wrong. For example, I would write instructions. I would get the work product back; I would call and say this needs to be updated, it was not done right. India's response was always no it's not in the instructions. I would go back and, in detail, review the instructions. It was right there in plain English. So then, I would go back, and they wouldn't admit it wasn't done or wasn't right, but they wouldn't do what my instructions said.

\subsection{Emotional intelligence overview}

EI is "the ability to perceive accurately, appraise, and express emotion; the ability to access and/or generate feelings when they facilitate thought; the ability to understand emotion and emotional knowledge; and the ability to regulate emotions to promote emotional and intellectual growth" (Mayer \& Salovey, 1997: 10). Mayer and Salovey (1997) separate EI into four sub-components or branches.

1. Perceiving emotions: The ability to perceive emotions in oneself and others as well as in objects, art, stories, music, and other stimuli;

2. Using emotions: The ability to generate, use, and feel emotion as necessary to communicate feelings or employ them in other cognitive processes;

3. Understanding emotions: The ability to understand emotional information, to understand how emotions combine and progress through relationship transitions, and to appreciate such emotional meanings;

4. Managing emotions: The ability to be open to feelings, and to modulate them in oneself and others to promote personal understanding and growth.

EI has explanatory power beyond traditional measures of intelligence and psychological profiles tests such as the five-factor model. EI has been found to 
have a predictive ability that goes above and beyond traditional predictors of success. For example, in a meta-study using a sample of over 5,000 subjects, O'Boyle et al. (2011) confirm that the level of EI has predictive value for job performance beyond that attributable to cognitive ability and the five-factor model. Further, research has shown a positive relationship between EI and many psychological and business phenomena. The relevant major issues and associated articles are as follows:

1. EI has been linked to organizational performance, quality of relationships, and employee well-being. Other studies in the management and organizational psychology literature, have demonstrated links between organizational performance, quality of relationships, and employee well-being (Kearney et al., 2017; Brackett et al., 2006; Côté \& Miners, 2006; Lopes et al., 2004).

2. EI has also been touted as essential to the performance and decision-making ability in a team environment (Druskat \& Wolff, 2001; Goleman et al., 2002; Rego et al., 2007). A team's ability to make good decisions comes with greater member abilities to communicate with one another, to be receptive to diverging opinions and to utilize emotion to improve team decision making.

3. EI level has been linked to both placement success and subsequent success of graduates (Boyatzis et al., 2002; Boyatzis \& Saatcioglu, 2008; Joyner \& Mann, 2011). U.S. domestic research shows that significant use is made by U.S. businesses of screening and training for the desired EI traits (Fisher \& Ashkanasy, 2000; Choi et al., 2011; Kluemper et al., 2013).

In the field of accounting, EI and the ability to frame communication is particularly valuable in a high context firm, such as an audit firm. Helen Brand, CEO of ACCA, in her forward to the ACCA Report on Emotional Quotient in a digital age (ACCA, 2018) observes:

To the casual observer, emotions and accountancy can seem like unrelated concepts from two separate worlds. But to succeed in a fast-evolving digital age, professional accountants need a rounded set of skills that go beyond technical knowledge, and these skills include emotional intelligence.

EI is seen as a prerequisite for candidates being hired by global firms (Chia, 2005). The demand for emotionally intelligent hires has grown in the U.S. and Canada. Articles including Daff et al. (2012), and Bay and McKeage (2006) find that employers agree that better candidates have higher levels of EI. Chia (2005) finds that graduates with high levels of EI receive more offers from big four multinational accounting firms. 
Higher EI scores are seen as improving auditor skills and audit outcomes. Yang et al. (2015: 83) note that "the moderating influence of EI can effectively reduce auditors' tendency to engage in dysfunctional behavior and improve audit quality. Further, moderation analysis suggests that EI is an important mechanism that moderates the effects of different types of pressure on auditors' judgments."

\subsection{International business, national culture, and emotional intelligence}

When Hofstede (1994: 1) asserted that "the business of international business is culture," he appears to have been correct. A Google Scholar search for articles on the relationship between culture and global management practice and effectiveness alone brings up over 2.3 million citations and over 100 meta-studies (see Kirkman et al., 2006 and 2017 for a summary). After reviewing some 1141 articles, Stahl and Tung (2015, p. 391) confirm the dominant role of culture in the International Business literature thus:

Since the publication of Hofstede's seminal work, Culture's Consequences: International Differences in Work-related Values (1980), for better or for worse, his cultural dimensions have become an integral component of international business (IB) research.

However, there is minimal research that has examined the role of national culture in shaping one crucial skill that businesses require their employees to have: EI. Before 2003, most EI studies assumed that this concept had universal applicability (Mayer et al., 2001; Moon, 2011). Beginning with Antoniakis (2003, 2004), there has been increasing questioning of the universality of EI. Both Mayer et al. (2008), and Walter et al. (2011) identify cross-cultural dimensions in EI as an area which needs addressing. Walter et al. (2011: 54) set up the challenge thus:

A key research opportunity involves adopting a cross-cultural perspective when examining the role of EI for leadership. A first step is constructive replication of previous findings in other cultures. Beyond this, future research on EI and leadership should consider specific cultural dimensions (e.g., power distance, individualism, or masculinity; Hofstede, 2001) as potential moderators.

An updated version of this study is a literature review by Huynh et al. (2018). They are using the Joseph and Newman (2010) model which amends Mayer and Salovey (1997) to eliminate Branch 2 (using emotions). Huynh et al. (2018: 129) conclude that powerful "emotion processes vary substantially as a function of cultural differences. These differences, however, have largely been neglected in the study of EI. We see this as a major limitation of the EI construct and suggest that, without considering cultural differences in emotion processes, current EI models lack the breadth to address the broad range of effects on leadership, well-being, and relationships they purport to explain." 
Only a few studies have attempted to fill this gap. Karim and Weisz (2010) for example, provide a dual test of the MSCEIT Scale and the outcomes in two very different countries' France and Pakistan. Karim and Weisz (2010) find the more communitarian Pakistani students score significantly lower in mean total EI than the individualist French students. Moon (2011) finds a positive relationship of levels of EI with Singelis et al.'s (1995) cultural value of horizontal individualism which includes the conception of an autonomous individual and emphasis on equality. Moon (2011) argues that these cultural differences help account for differences in the MSCEIT dimension and sub-dimension scores between Anglo-North American and East Asian members of the sample. North Americans include both U.S. and Canadian students. Anglo indicates persons of European origin, specifically persons whose ancestors come from the British Isles but are born in Canada. The term East Asians is used to describe people who are Chinese, Hong Kong Chinese, Taiwanese, Japanese, or Korean (Heine et al., 1999; Nisbett, 2003; Oyserman et al., 2002). Moon (2011) finds that:

1. Anglo-North Americans score significantly higher in total EI than East Asians on The MSCEIT test battery.

2. Horizontal individualism helps explain why Anglo-North Americans who are more score higher. The argument is that Anglo-North American is driven by their culture to act individually and seek a one-on-one emotional melding or point of persuasion with similarly individualistic and low power distance colleagues and clients.

After a literature review of studies focusing primarily on Chinese and Japanese subjects, Huynh et al. (2018) find that subjects from independent (individualistic) cultures not only use emotion better externally, they are also more confident in their judgment.

Presenting the opposite point of view, Gunkel et al. (2014) come to different conclusions from most of the previous literature on the effect of culture dimensions on EI. Using a sample of nine countries and the Wong and Law (2002) self-report scoring system, Gunkel et al. (2014: 268) find that "collectivism, uncertainty avoidance, and long-term orientation have a positive effect on the four facets of EI." Gunkel et al. (2014: 268) also conclude "the ability of self-emotional appraisal may function as a coordination mechanism within collective societies... [and] that individuals scoring high in uncertainty avoidance might be observing others' emotions more thoroughly to avoid any future uncertainties." One concern is that the statistical power of Gunkel et al. (2014) varies considerably from country to country. Many of the results have what Gunkel et al. (2014) refer to as modest support with $\mathrm{p} \leq 0.10$. Thus, we form our hypotheses on the earlier but more statistically significant work. 


\subsection{Summary extension and hypotheses}

The extant literature indicates that it is likely but not certain that different countries will have different levels of emotional intelligence. It is likely but again uncertain that countries with lower levels of individualism will have lower levels of EI. While it is possible that each country's EI levels are appropriate for that country and culturally similar countries, significant problems may occur if countries with very different cultures and levels of EI enter into commercial relationships. Low EI countries may not provide the amount of emotional spin or apparent restraint to serve higher EI clients. Higher EI countries, in turn, may interpret fewer positive responses as signs of failure or poor communication.

Given the existence of this client/supplier relationship inherent in offshoring within the audit firm, a picture of the EI levels or a predictable culture to EI relationship for India and the U.S. is crucial. To expand the cultural research on EI, we measure and compare levels of EI in India and the U.S. Whether one uses the Hofstede (1980), Hofstede et al. (2010), or House et al. (2004) data, the U.S. is on one end of most scalar measures and India is on the other end. Table 1 provides data on the Hofstede cultural dimension for India and the U.S. India scores higher than the U.S. on the power distance and long-term orientation cultural dimensions, and lower than the U.S. on the individualism, masculinity and uncertainty avoidance cultural dimensions.

Table 1. Hofstede's cultural scores

\begin{tabular}{ccc}
\hline Index Scores & United States & India \\
\hline Power Distance (PD) & 40 & 77 \\
Individualism (IDV) & 91 & 48 \\
Masculinity (MAS) & 62 & 56 \\
Long-term Orientation (LTO) & 26 & 51 \\
Uncertainty Avoidance (UA) & 46 & 40 \\
\hline
\end{tabular}

(Source: The cultural scores can be obtained by visiting the following link to Hofstede's website at https://www.hofstede-insights.com/product/compare-countries/)

Following the predominance of the extant literature, the U.S. subjects being both individualist and low in power distance should have a higher MSCEIT EI score than the subjects from India. Indian subjects, being collectivists, are less likely to perceive, use, understand and manage emotions. Coming from a collectivist society they believe their intentions will be understood and, using high power distance, they do not need to accommodate the emotions of others. Of course, it is possible that moderating variables such as age and gender may affect the results, and these are added as control variables. 
Building upon the previous literature review, we propose the following hypotheses:

H1: Respondents from the U.S. will a have a higher total emotional intelligence than those from India.

H2: Respondents from the U.S. will have a higher ability to perceive, use, understand, and manage emotions than those from India.

\section{Methodology}

After the publication of Goleman's (1995) book on EI, many authors had different approaches to defining and measuring EI. Our first task, methodological choice, therefore, was to select an EI model and measurement instrument. Several alternative questionnaires are available to measure the different models of EI. These measures can, in turn, be broken into trait-based and ability-based models., In our study, we rely on McEnrue and Groves' (2006) meta-study which supports the use of Mayer-Salovey-Caruso EI test. McEnrue and Groves (2006: 38) conclude that "We have advocated the MSCEIT based on its psychometric properties and HRD application potential." MSCEIT is an ability-based test designed to measure total EI and four branches of EI (see Table 2). The questionnaire is not available for public release even to reviewers. However, with the permission of the administering body of MSCEIT, Multi-Health Systems, examples of specimen questions are provided in the Appendix.

We collected data both on overall EI and the sub-measures or branches of EI. As Mayer et al. (2008: 507) note:

Each branch describes a set of skills that make up overall emotional intelligence. Each branch has its developmental trajectory, proceeding from relatively easy skills to more sophisticated ones. For example, Perceiving Emotions typically begins with the ability to perceive basic emotions in faces and voice tones and may progress to the accurate perception of emotional blends and the detection of emotional microexpressions in the face.

We collect the English language data using the online survey developed by MSCEIT (Mayer, 2002). The survey is a 141 item, is an ability-based test of EI that helps to identify a person's ability to identify emotions in others, to use emotions to facilitate thought, to understand emotional meanings, and to know how to manage emotions. The good news is that the MSCEIT has been widely used and has been accepted in the major journals in Management, Marketing, and Psychology. A 
Google Scholar search finds the MSCEIT survey has been used about 5600 times in articles published in high-quality journals.

Table 2. Mayer and Salovey's (1997) four-branch model of emotional intelligence

\begin{tabular}{l}
\hline $\begin{array}{l}\text { Branch (sub-component) } \\
\text { of Emotional Intelligence }\end{array}$ \\
\hline Perception of emotion
\end{tabular}

Brief Description of Skills Involved

The ability to perceive emotions in oneself and others, as well as in objects, art, stories, music and other stimuli

Use of emotion to

The ability to generate, use, and feel emotion as facilitate thinking necessary to communicate feelings, or employ them in other cognitive processes

Understanding of emotion The ability to understand emotional information, how emotions combine and progress through relationship transitions and to appreciate such emotional meanings

Management of emotion The ability to be open to feelings, to modulate them in oneself and others so as to promote personal understanding and growth

(Source: Brackett et al. (2006: 35))

Our second choice is that of sample selection and administration of the instrument. We collected data from master's students in accounting classes India and the U.S. because, in the past, they have been considered as reasonable substitutes for the managers (see for example, Gunkel et al., 2014). Some studies (Birditt \& Fingerman, 2003) find that participants' demographics also influence EI Scores. Therefore, data were also collected on two control variables, age and gender, and the following control variables were used in the study: age, gender, and age*gender interaction.

\subsection{Sample}

Our total sample was 197 master's students in accounting classes from universities in India and the U.S. The sample were $38 \%$ and $34 \%$ women in the U.S. and India respectively. The U.S. figure was slightly higher than the percentage of women graduating from business schools, which is $36 \%$ (Dishman, 2017). Interestingly, we also captured more women in the Indian sample. A typical Indian master's program normally contains between 5\% and 20\% women (Bhattacharyya, 2017). The U.S. sample was older than the Indian sample at 30 years old versus 25 years. 
This would make it slightly older than the typical full-time U.S. master's student in business (which is 28) but well within the range for part-time master's students in the business group (Mbacrystalball.com, 2013). The Indian master's students in business were on average 25 years old. This again is slightly older as Indian students usually go to master's programs directly from the undergraduate programs. This suggests that the Indian group had at least some work experience. However, as discussed later, our regression analyses show that age is only significant is Branch 4, managing emotions. Age, gender, and age*gender were not significant explanatory factors in other models. Table 3 provides demographics for our respondents.

Table 3. Demographics

\begin{tabular}{lcc}
\hline & United States & India \\
\hline Number of Respondents & 87 & 110 \\
Respondent Profile: & 49 & 75 \\
$\quad$ Males & 34 & 38 \\
$\quad$ Females & 0 & 1 \\
$\quad$ No Response & 30.77 & $25.44^{*}$ \\
Average Age & &
\end{tabular}

*Not all subjects provided demographic data. Average Age is calculated using data from108 respondents.

Table 4. Mean and median E.I. scores by country

\begin{tabular}{lccccc}
\hline \multicolumn{1}{c}{ Country/ E.I. } & $\begin{array}{c}\text { Perceiv- } \\
\text { ing }\end{array}$ & Using & $\begin{array}{c}\text { Under- } \\
\text { standing }\end{array}$ & Managing & Total E.I. \\
\hline India & & & & & \\
$\quad$ N= 110 & & & & & \\
Mean & 80.45 & 77.14 & 74.83 & 76.63 & 70.61 \\
SD & 16.40 & 17.25 & 13.68 & 11.33 & 14.94 \\
Median & 79.33 & 74.65 & 75.08 & 73.79 & 70.52 \\
& & & & & \\
United States & & & & & \\
$\quad$ = 87 & & & & & \\
Mean & 103.35 & 98.91 & 92.80 & 93.90 & 97.08 \\
SD & 14.22 & 14.26 & 10.69 & 8.79 & 11.61 \\
Median & 101.47 & 99.93 & 93.14 & 93.26 & 98.61 \\
& & & & & \\
Total & & & & & \\
$\quad$ N= 197 & & & & & \\
Mean & 90.56 & 86.75 & 82.76 & 83.00 & 82.30 \\
SD & 19.19 & 19.29 & 15.30 & 14.69 & 18.89 \\
Median & 90.70 & 86.05 & 85.50 & 86.00 & 83.57 \\
& & & & & \\
\hline
\end{tabular}


Figure 1: Mean emotional intelligence scores of U.S. and Indian respondents

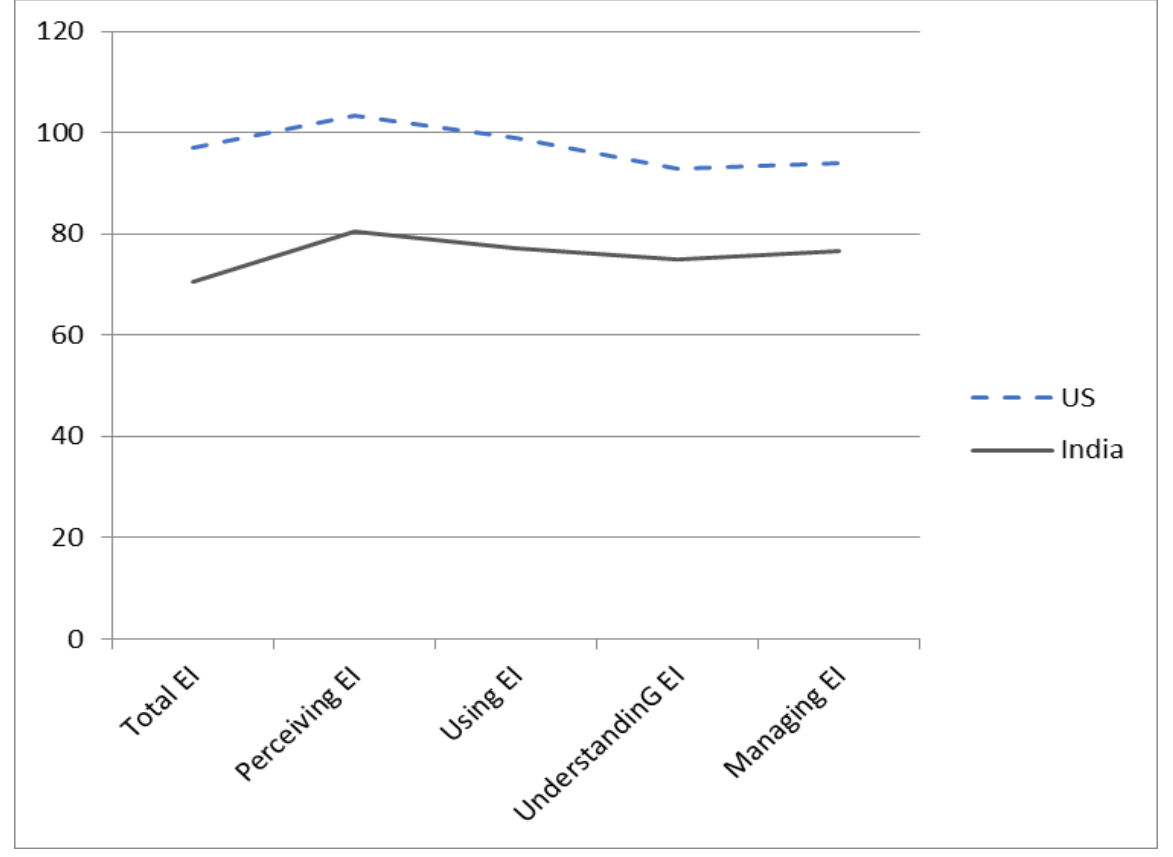

\section{Findings}

\subsection{Means, standard deviations, and median}

Table 4 reports the means, standard deviations, and median scores for total EI and its four branches (perceiving, using, understanding, and managing emotions) for each country. The mean total EI of U.S. students was 97.08 compared to 70.61 for Indian students.

As discussed earlier, EI is comprised of four branches (sub-components) or abilities which build on each other. They are perceived to operate in the following hierarchy from lowest to highest: Branch 1 - the perception of emotion; Branch 2 use of emotion to facilitate thinking; Branch 3 -understanding of emotion; and lastly, Branch 4 - management of emotion. Branches 1, 3, and 4 involve reasoning about emotions. Branch 2 (the use of emotions to facilitate thought) involves using emotions to enhance reasoning. Table 4 and Figure 1 present the mean EI scores for India and the U.S. We also examine inter-country variation on each of EI's branches. The Indian students had the lower EI on all the four branches perceiving, using, understanding, and managing emotions. 
The interpretation of the results begins with measures for each branch. The model presented by Mayer et al. (2008) sees each of the four branches being a prerequisite for success in the other branch and the overall score. As expected, both countries had their highest scores in the perceiving branch (Branch 1). This branch is regarded as a precursor to the other branches of EI, and the result is what we would expect. The pattern continues with Branches 2 and 3 having lower scores than the previous branch.

The Branch 4 score is higher in both countries than Branch 3 (managing emotions). This result is unexpected as scores should decline as the branches become more complex. However, the scores in the final two branches are identical for practical purposes. This indicates a leveling off within emotional intelligence once the subject achieves an understanding of their own and other persons' emotions.

Also interesting is that as the subjects move from perceiving to managing the standard deviation is reduced. Since the samples for each branch are the same, essentially the distribution becomes tighter. It appears that as subjects learn they become more confident of the correct answer.

\subsection{Formal test of the hypotheses}

To formally test the hypotheses, we use OLS regression. OLS regression enables us to include both indicator and continuous variables. We first test the total EI and then the branches. Total EI is first regressed on the country indicator variable (India $=0$, US $=1$ ), age, gender (scored as a $1 / 0$, male/female dummy variable), and an age*gender interaction. Table 5 describes the results of the first OLS regression. The regression has an adjusted R-Square of 0.493 and is significant at $\mathrm{p}$-value $<.001$. The country dummy variable is significant and positive at ( $\mathrm{p}$-value $<0.001)$. Age, gender, and age*gender are not significant.

This result suggests that total EI differs between India and the US. The country beta is positive, indicating that the subjects from the U.S. had a higher EI level than the Indian subjects. This supports H1. This is hardly surprising given the raw numbers, but it supports the view that India, and by association other communitarian countries, have a lower overall emotional intelligence score.

The insignificance of the demographic variables is in line with previous studies that have found no significant effect of gender on EI (Nikolaou \& Tsaousis, 2002; Whitman et al., 2009). It challenges many earlier studies that find that women have higher emotional intelligence (Day \& Carroll, 2004; Mandell \& Pherwani, 2003; Van Rooy et al., 2005). 
Table 5. Regression results on total EI or branch EI as the dependent variable

Model: Total EI (or Branch EI) $=\alpha+\beta_{1}$ Age $+\beta_{2}$ Gender $+\beta_{3}$ Age*Gender + $\beta_{4}$ Country $+\mu$

\begin{tabular}{|c|c|c|c|c|c|}
\hline & $\begin{array}{c}\text { Total } \\
\text { EI }\end{array}$ & $\begin{array}{c}\text { Perceiving } \\
\text { EI }\end{array}$ & $\begin{array}{c}\text { Using } \\
\text { EI }\end{array}$ & $\begin{array}{c}\text { Understanding } \\
\text { EI }\end{array}$ & $\begin{array}{c}\text { Managing } \\
\text { EI }\end{array}$ \\
\hline Intercept & $\begin{array}{c}38.45 * * * \\
(6.25)\end{array}$ & $\begin{array}{c}60.81 * * * \\
(7.21)\end{array}$ & $\begin{array}{c}51.24 * * * \\
(7.28)\end{array}$ & $\begin{array}{c}50.73 * * * \\
(5.79)\end{array}$ & $\begin{array}{c}50.31 * * * \\
(4.86)\end{array}$ \\
\hline Age & $\begin{array}{c}0.41 \\
(0.24)\end{array}$ & $\begin{array}{l}-0.01 \\
(0.7)\end{array}$ & $\begin{array}{c}0.43 \\
(0.27)\end{array}$ & $\begin{array}{c}0.33 \\
(0.22)\end{array}$ & $\begin{array}{l}0.435^{*} \\
(0.18)\end{array}$ \\
\hline $\begin{array}{c}\text { Gender } \\
(\text { Female = 0; } \\
\text { Male = 1) }\end{array}$ & $\begin{array}{c}0.96 \\
(7.87)\end{array}$ & $\begin{array}{l}-5.53 \\
(9.07)\end{array}$ & $\begin{array}{l}-8.37 \\
(9.16)\end{array}$ & $\begin{array}{l}5.13 \\
(7.28)\end{array}$ & $\begin{array}{c}6.07 \\
(6.12)\end{array}$ \\
\hline Age*Gender & $\begin{array}{c}0.16 \\
(0.28)\end{array}$ & $\begin{array}{c}0.08 \\
(0.32)\end{array}$ & $\begin{array}{l}0.15 \\
(0.33)\end{array}$ & $\begin{array}{l}-0.24 \\
(0.26)\end{array}$ & $\begin{array}{l}-0.32 \\
(0.22)\end{array}$ \\
\hline $\begin{array}{l}\text { Country (India } \\
=0 ; \mathrm{US}=\mathbf{1})\end{array}$ & $\begin{array}{c}24.18 * * * \\
(2.15)\end{array}$ & $\begin{array}{c}22.30 * * * \\
(2.48)\end{array}$ & $\begin{array}{c}18.32 * * * \\
(2.51)\end{array}$ & $\begin{array}{c}16.60 * * * \\
(1.99)\end{array}$ & $\begin{array}{c}16.93 * * * \\
(1.67)\end{array}$ \\
\hline R-Square & 0.503 & 0.360 & 0.354 & 0.352 & 0.461 \\
\hline $\begin{array}{l}\text { Adjusted R- } \\
\text { Square }\end{array}$ & 0.493 & 0.347 & 0.341 & 0.338 & 0.450 \\
\hline $\mathbf{N}$ & 197 & 197 & 197 & 197 & 197 \\
\hline Model p-value & $<0.001$ & $<0.001$ & $<0.001$ & $<0.001$ & $<0.001$ \\
\hline
\end{tabular}

Standard errors are reported in parentheses;

$* * *$ Significant at $\mathrm{p}<0.001, * *$ Significant at $\mathrm{p}<0.01$; *Significant at $\mathrm{p}<0.05$.

Table 5 also reports the result of regressing scores for each of the branches or subcomponents of EI (perceiving, using, understanding, and managing emotions) on the country variable (India $=0$, US $=1$ ), age, gender, and the age*gender interaction. We find that all regression models for the EI branches are significant (p-value <0.001). In all regressions for the branch dependent variables, the independent variable, country, has a positive and significant beta indicating that U.S. subjects had a higher score on the branches of EI after controlling for the three demographic variables. The regression results suggest that scores on all branches of EI are lower in India than the U.S. This result supports H2. 
We note that the inter-country difference as measured in t-value increases. This is one sign that the cascade continues from perception to managing emotions. For one branch of EI, the managing of emotions, both the country variable and the age demographic variable (p-value $<0.05)$ are significant. The results confirm that culture matters and the U.S. continues to dominate. The results indicate that older subjects are more open to feelings and better able to modulate their impact on themselves and others. Their ability to manage emotions, in turn, allows for greater personal understanding and growth, and ultimately achieving their preferred outcome.

Since managing emotions is considered the objective of completing the EI cascade, it appears that age, and by association experience, matters. This has some interesting implications for master's and other educational programs. While EI can be taught, it seems that the final and most crucial stage also requires the process and repetition of the same emotional situation in the workforce. In essence, this skill becomes a learned ability rather than an intuitive ability. This is the main effect and applies, regardless of culture.

Gender provided no significant explanatory power for the sub-components of EI (perceiving, using, understanding and managing emotions) either as a main effect or as part of an age*gender interaction.

In summary, our regressions show that country (cultural values) is the significant variable in explaining the total EI score and the score on each branch (sub-component) of EI. Even after controlling for age and gender, the U.S., an individualist and lower power distance country, has a higher score on total EI and its branches (subcomponents).

\section{Discussion and conclusion}

The results provide evidence that persons from India, a collectivist country, have lower scores on EI than persons from the individualist U.S. These results support H1. They also add further credibility to the work of Moon (2011) and Karim and Weisz (2010). The results provide evidence that persons from India, a collectivist country, have lower scores on EI than persons from the individualist U.S. These results support H1. They also add further credibility to the work of Moon (2011) and Karim and Weisz (2010). 
Figure 2. Mean emotional intelligence of the available Asian vs Western countries

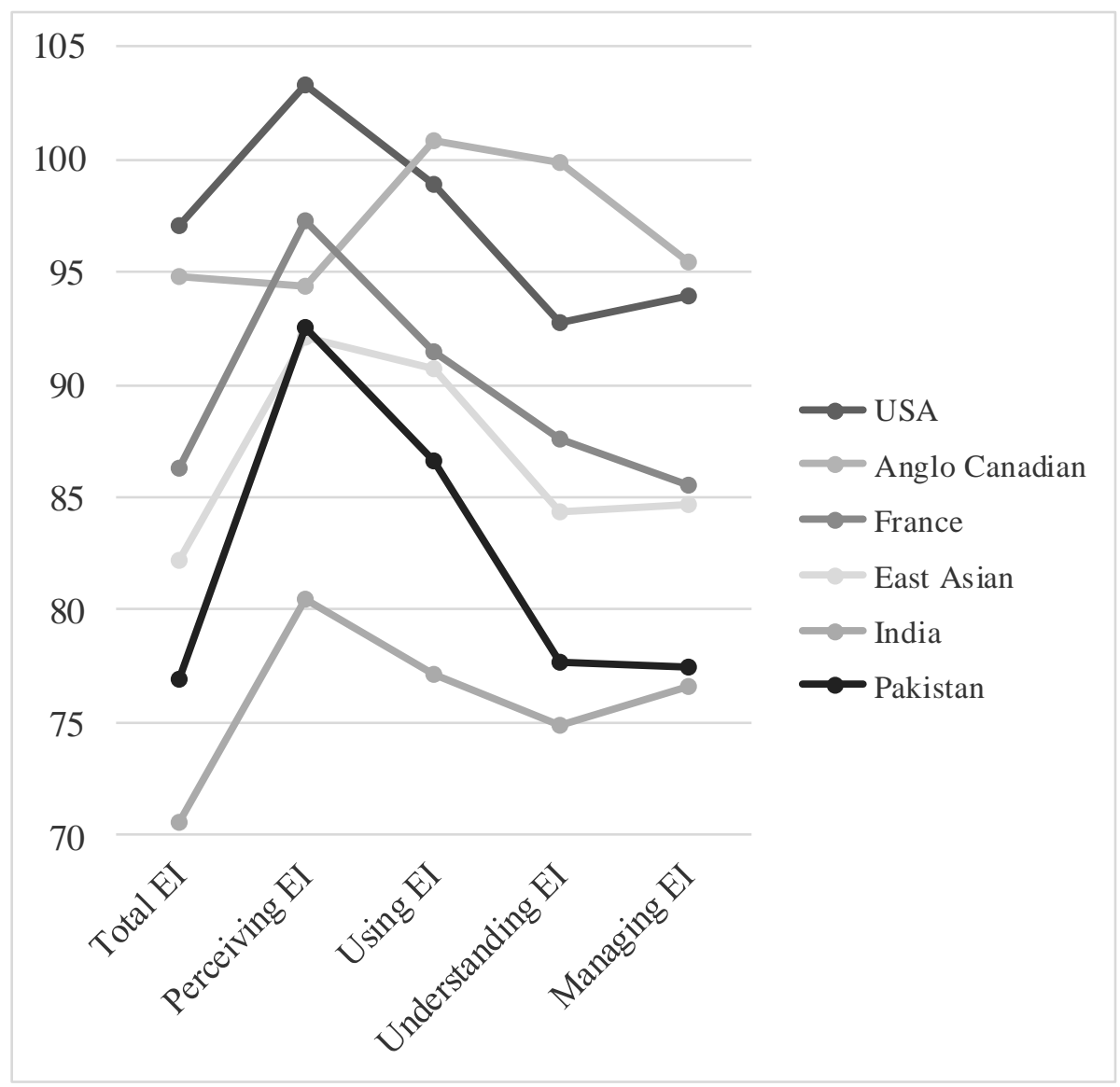

However, we need to ask, why do we get this result? It is possible that this is because Indians are relatively communitarian; they do not need to cultivate the understanding of oneself and fellow subjects to be effective. While being part of a community would indicate the need to understand the emotions of the group, this may already be in place in the norms of work and other social interactions. Also, if there is group consensus, it may even be inappropriate to attempt to collect and use the information on feelings to manipulate the feelings and actions of others. We suspect that the Indian subjects feel safer within their group and have less need to manage their emotions and present an always positive message. U.S. students, by contrast, are required to show positive attitudes and manage their emotional message.

Vol. 18, No. 2 
Figure 3. Mean emotional intelligence of the individualist vs collectivist countries

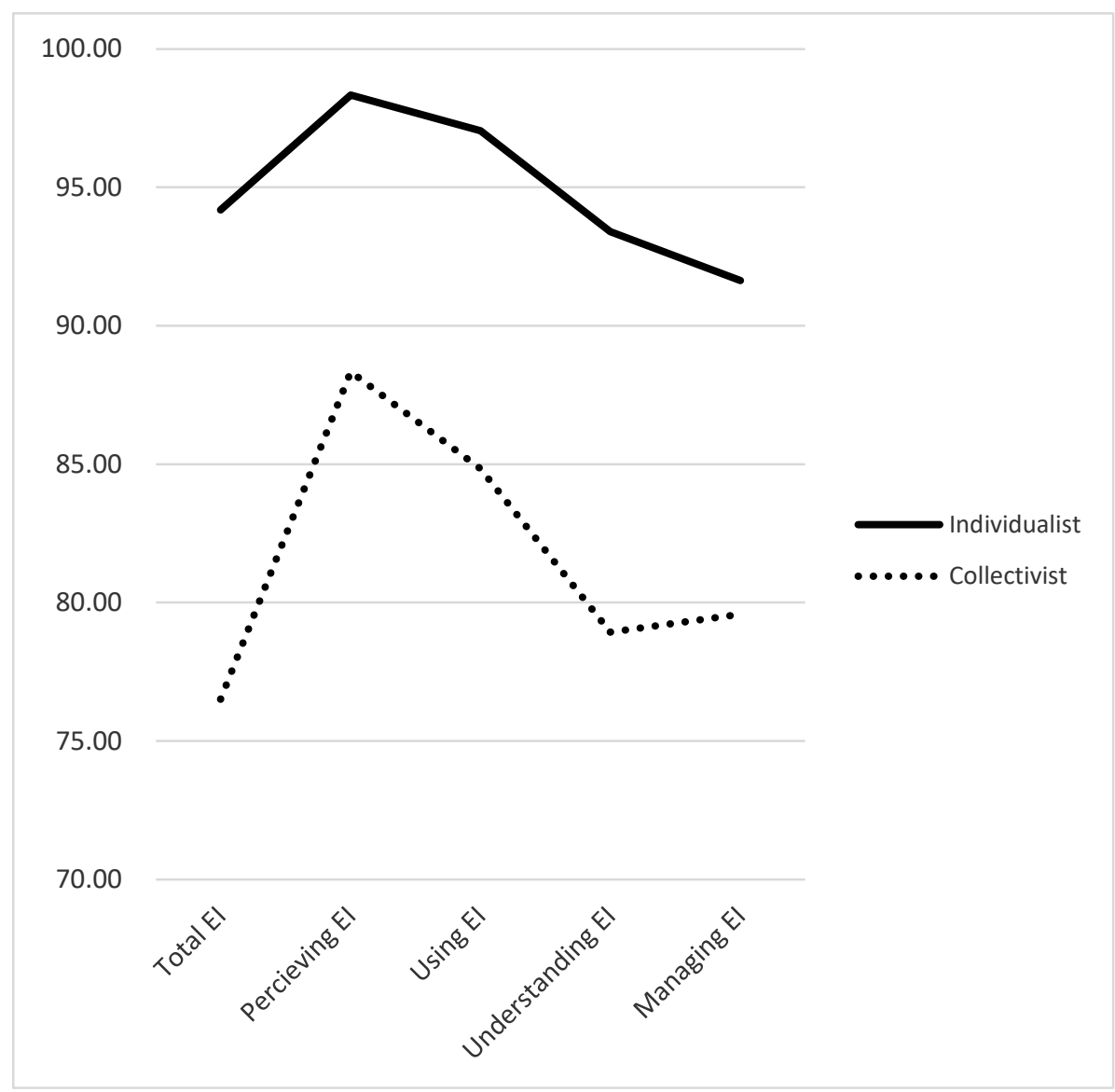

Further, we cannot discount the class distinction in that the Indian master's students in business are typically in the Indian upper middle-class and are not taught the need to control what one says (Grossmann \& Huynh, 2013). As evidence of this upper middle-class bias, approximately 30,000 Indians took the GMAT out of a population of 1.3 billion in 2016. The U.S. master's programs reach much deeper into the population. In 2016, 82,000 took the GMAT out of a population of 325 million (Countryeconomy.com, 2016; Mbacrystalball.com, 2013)). This is a rate of approximately 10 times that of India.

Academically, one can ask is India typical for a communitarian country. While we do not have access to the raw data of other studies, Figures 2 and 3 combine the results of this study with those of two previous studies, Moon (2011) and Karim 
and Weisz (2010). Figure 3 clearly shows that individualist countries dominate the collectivist countries in all aspects of EI. Given that all the studies use the same instrument and scale, this seems like compelling evidence that individualist societies have higher levels of EI. However, if one examines Figure 2 which is a country-based chart over a similar scale the evidence is more fractured. Using Branch 4, India and Pakistan have the lowest levels of EI. Anglo Canada and the U.S. have the highest skills in this area. However, in the middle, France and East Asian subjects (Koreans and Chinese) are almost identical. Given that the East Asian group includes subjects from Korea and Hong Kong, it is possible that some other dimension is the part of the equation.

\subsection{Lessons for the profession}

Given our findings, we believe there are lessons here for accounting firms. When using Indian employees to serve as members of their extended team, global and other audit firms need to understand that they are working within a very different culture. These cultural differences lead to different EI levels in different national offices of the same company. The literature indicates that these differences are likely to disrupt the smooth functioning of the organization, and negatively influence organizational efficiency and output. Organizations need to be able to understand the emotions and communication abilities of offshoring employees and not just assume that they will be the same as home country employees.

The positive aspect of India's low EI is that EI skills are trainable and upgradable. Cook et al. (2011) identify global firms that train their staff to improve their emotional intelligence skills. Many U.S. business schools teach and coach master's students to improve EI skills (Joyner \& Mann, 2011; Nelis et al., 2009; Pool \& Qualter, 2012; Sigmar et al., 2010; Herpertz et al., 2016; Rodriguez et al., 2017). The change is also rapid. Nelis et al. (2009) found that even six months training could improve EI scores. However, since U.S. firms would have to pay for this, it will most certainly increase the cost of offshoring.

We also believe that if India is to continue and grow as the back office of the world, Indian educational institutions need to increase EI capabilities and training. Kearney et al. (2017) find that low emotional intelligence of back-office staff can reduce organizational performance. Failures of communication, lack of understanding of the needs of clients to do the work right the first time, and the inability to collaborate on solving the problem, also reflect a lack of understanding of the emotional drivers of the client. This, in turn, leads to an inability to build trust. This resonates in this quote from an audit manager in Downey (2018: 222): 
I wouldn't trust an [offshore audit] staff as much as I trust my own [audit] staff. So it makes me take more time out of my already filled schedule, with relatively no time to give to these types of things. I have to spend more time, and then the senior has to spend more time, reviewing these items that we typically wouldn't spend a couple hours reviewing. Well I have to spend a couple hours reviewing now, because I want to make sure they didn't screw something up. (A01)

We also argue that the Indian offshoring sector may also be able to resolve high employee turnover problems by recognizing and resolving the EI problem. Ranganathan and Kuruvilla (2008) report that the Indian BPO sector suffers from high turnover problems driven by a lack of emotional intelligence among senior and middle managers. In a similar vein, Ho et al. (2012: 12) argue that "Indian BPO firms will need effective employee selection and retention strategies to sustain their growth." By developing their EI skills, the students and professionals will be able to advance their careers.

\section{Limitations and future research}

First, there may be some limitation in the generalizability of the findings of our study as we focused on two countries, the U.S. and India. Future research could examine the EI scores of other countries such as China, Vietnam, Malaysia, and the Philippines, which are other offshoring centers of U.S. and European companies. Also of interest would be South Africa, which has been a recipient of legal process offshoring (Davies, 2014). Samples from other major offshoring countries of origin, including the U.K. and Australia, would add to the overall understanding of role of EI in the offshoring environments.

Second, the data for this research was collected from master's students using the MSCEIT instrument, and although the use of master's students in accounting classes as the research participants is well documented in prior research, it is possible that master's students may not adequately reflect the average EI levels in different countries.

Future research could expand on our findings to further explain the role of EI in the success of offshoring arrangements. It would be helpful to link values, emotional intelligence, and communication or audit tasks directly. This provides a significant amount of work and future development opportunities. " 


\section{References}

Andiola, L.M., Downey, D.H., Spilker, B.C. \& Noga, T.J. (2018) “An examination of the interactive effect of feedback source and sign in the offshoring environment: A social identity perspective", Behavioral Research in Accounting, vol. 30, no. 2: 1-21

Antoniakis, J. (2004) "On why 'emotional intelligence' will not predict leadership effectiveness beyond IQ or the 'big five': An extension and rejoinder", International Journal of Organizational Analysis, vol. 12, no. 2: 171-182

Antoniakis, J. (2003) "Why "emotional intelligence" does not predict leadership effectiveness: A comment on Prati, Douglas, Ferris, Ammeter, and Buckley (2003)", The International Journal of Organizational Analysis, vol. 11, no. 4: 355-361

Bhattacharyya, R. (2017) "Growing presence of women in India's MBA institutes",

https://economictimes.indiatimes.com/industry/services/education/growingpresence-of-women-in-indias-mba-institutes/articleshow/57999252.cms. Accessed May 62019

Bay, D. \&. McKeage, K. (2006) "Emotional intelligence in undergrad accounting students: Preliminary assessment", Accounting Education, vol. 5, no. 4: 439-454

Birditt, K.S. \& Fingerman, K.L. (2003) “Age and gender differences in adults' descriptions of emotional reactions to interpersonal problems", The Journals of Gerontology Series B: Psychological Sciences and Social Sciences, vol. 58, no. 4: 237-245.

Boyatzis, R.E \& Saatcioglu, A. (2008) "A 20-year view of trying to develop emotional, social and cognitive intelligence competencies in graduate management education", Journal of Management Development, vol. 27, no. 1: $92-108$

Boyatzis, R.E., Saatcioglu, A., Stubbs, E.C. \& Taylor, S.N. (2002) "Learning cognitive and emotional intelligence competencies through graduate management education", Academy of Management Learning \& Education, vol. 1, no. 2: $150-162$

Brackett, M.A, Rivers, S.E., Shiffman, S., Lerner, N. \& Salovey, P. (2006) "Relating emotional abilities to social functioning: a comparison of selfreport and performance measures of emotional intelligence", Journal of Personality and Social Psychology, vol. 91, no. 4: 780-795

Buckley, P.J. \& Ghauri, P.N. (2004) "Globalisation, economic geography and the strategy of multinational enterprises", Journal of International Business Studies, vol. 35, no. 2: 81-98

Chia, Y.M. (2005) "Job offers of multi-national accounting firms: The effects of emotional intelligence, extra-curricular activities, and academic 
performance", Accounting Education: An International Journal, vol. 14, no. 1: 75-93

Choi, S., Kluemper, D.H. \& Sauley, K.S. (2011) "What if we fake emotional intelligence? A test of criterion validity attenuation", Journal of Personality Assessment, vol. 93: 270-277

Cook, G.L., Bay, D., Visser, B., Myburgh, J.E. \& Njoroge, J. (2011) "Emotional intelligence: The role of accounting education and work experience", Issues in Accounting Education, vol. 26, no. 1: 267-286

Côté, S. \& Miners, C.T.H. (2006) "Emotional intelligence, cognitive intelligence, and job performance", Administrative Science Quarterly, vol. 51, no. 1: 1-28

Countryeconomy.com (2016) https://countryeconomy.com/countries/compare/ india/usa. Accessed May 82019

Daff, L., De Lange, P., \& Jackling, B. (2012) "A closer look at how emotional intelligence may be used to enhance generic skills development in accounting education" in "Proceedings of accounting and financial association of Australia and New Zealand Conference (AFAANZ 2012). Carlton, Australia, 1-3 July; 1-32

Davies, R. (2014) "South Africa growing as legal outsourcing host", https://www.iol.co.za/business-report/opinion/sa-growing-as-legaloutsourcing-host-1763835. Accessed May 82019

Day, A.L. \& Carroll, S.A. (2004) "Using an ability-based measure of emotional intelligence to predict individual performance, group performance, and group citizenship behaviours", Personality and Individual Differences, vol. 36, no. 6: 1443-1458

Deloitte (2015) Deloitte's 2014 global outsourcing and insourcing survey, https://www2.deloitte.com/content/dam/Deloitte/us/Documents/strategy/us2014-global-outsourcing-insourcing-survey-report-123114.pdf. Accessed August 92017

Dishman, L. (2017 "The hidden gender gap among MBA graduates", https://www.fastcompany.com/40447757/the-hidden-gender-gap-amongmba-graduates.Accessed May 62019

Downey, D.H. (2018) "An exploration of offshoring in audit practice and the potential consequences of associated work "re-design" on auditor performance", Auditing: A Journal of Practice and Theory, vol. 37, no. 2: 197-224

Druskat, V.U. \& Wolff, S.B. (2001) "Building the emotional intelligence of groups", Harvard Business Review, vol. 79, no. 3: 80-91

Farrell, D. (2005) "Offshoring: Value creation through economic change", Journal of Management Studies, vol. 42, no. 3: 675-683

Fisher, C.D., \& Ashkanasy, N.M. (2000) "The emerging role of emotions in work life: An introduction", Journal of Organizational Behavior, vol. 21: 123-129

Goleman, D., Boyatzis, R. \& McKee, A. (2002) "The emotional reality of teams." Global Business and Organizational Excellence, vol. 21, no. 2: $55-65$ 
Goleman, D. (1995) E.I.: Why it can matter more than IQ, New York, NY: Bantam Books

Grossmann, I. \& Huynh, A. C. (2013) "Where is the culture in social class?", Psychological Inquiry, vol. 24: 112-119

Gunkel, M., Schlägel, C. \& Engle, R.L. (2014) "Culture's influence on emotional intelligence: An empirical study of nine countries", Journal of International Management, vol. 20, no. 2: 256-274

Heine, S.J., Lehman, D.R., Markus, H.R. \& Kitayama, S. (1999) "Is there a universal need for positive self-regard?" Psychological Review, vol. 106, no. 4: 766-794

Herpertz, S., Schütz, A. \& Nezlek, J. (2016) "Enhancing emotion perception, a fundamental component of emotional intelligence: Using multiple-group SEM to evaluate a training program", Personality and Individual Differences, vol. 95: 11-19

Ho, V., Whitaker, J., Mithas, S. \& Roy, P.K. (2012) "It's what's inside that counts: the role of social and psychological capital in compensation for offshore BPO professionals", https://aisel.aisnet.org/icis2012/proceedings/ GlobalIssues/3/, Accessed December 212018

Hofstede, G. (1980) Culture's consequences: National differences in thinking and organizing, Beverly Hills: CA Sage Publications

Hofstede, G. (1994) "The business of international business is culture", International Business Review, vol. 3, no. 1: 1-14

Hofstede, G. (2001) Culture's consequences: Comparing values, behaviors, institutions and organizations across nations, Thousand Oaks California: Sage publications

Hofstede, G., Hofstede, G.J. \& Minkov, M. (2010) Cultures and Organizations: Software of the mind, New York, NY: McGraw Hill

House, R.J., Hanges, P.J., Javidan, M., Dorfman, P.W. \& Gupta, V. (eds.). (2004) Culture, Leadership, and Organizations: The GLOBE Study of 62 Societies, Thousand Oaks, CA: Sage Publications,

Huynh, A.C., Oakes, H. \& Grossmann, I. (2018) "The role of culture in understanding and evaluating emotional intelligence", Emotional Intelligence in Education, K. V. Keefer, J. D. Parker, \& D. H. Saklofske (Eds.), Springer: New York, pp. 111-132

Jain, A. (2015) "Out of three lakh master's graduates every year, only $10 \%$ are employable: Experts", http://articles.economictimes.indiatimes.com/201501-13/news/58024327_1_aicte-institutes-parag-kalkar. Accessed on December 42016

Joseph, D. L. \& Newman, D. A. (2010) "Emotional intelligence: An integrative meta-analysis and cascading model", Journal of Applied Psychology, vol. 95 : 54-78 
Joyner, F.F. \& Mann, D.T.Y. 2011 "Developing emotional intelligence in master's students: A case study of one program's success", American Journal of Business Education, vol. 4, no. 10: 59-72

Karim, J. \& Weisz, R. (2010) "Cross-cultural research on the reliability and validity of the Mayer-Salovey-Caruso Emotional Intelligence Test (MSCEIT)", Cross-Cultural Research, vol. 44, no. 4: 374-404

Kearney, A.T. Global Services Location Index report (2017). athttps://www.atkearney.com/documents/20152/793366/The+Widening+Im pact+of+Automation.pdf/42b06cf4-e5f9-d8ec-a30c-a82dd26d4953. Accessed on December 202018

Kearney, T., Walsh, G., Barnett, W., Gong, T., Schwabe, M. \& Ifie, K. (2017) "Emotional intelligence in front-line/back-office employee relationships", Journal of Services Marketing, vol. 31, no. 2: 185-199

Kirkman, B.L., Lowe, K.B. \& Gibson, C.B. (2006) "A quarter century of culture's consequences: A review of empirical research incorporating Hofstede's cultural values framework", Journal of International Business Studies, vol. 37, no. 3: 285-320

Kirkman, B.L., Lowe, K.B. \& Gibson, C.B. (2017) "A retrospective on culture's consequences: The 35-year journey", Journal of International Business Studies, vol. 48, no. 1: 12-29

Kluemper, D.H., DeGroot, T. \& Choi, S. (2013) "Emotion management ability: Predicting task performance, citizenship, and deviance", Journal of Management, vol. 39: 878-905

Larsen, M.M., Manning, S. \& Pedersen, T. (2011) "The hidden costs of offshoring: The impact of complexity, design orientation and experience", In Academy of Management Proceedings, vol. 1: 1-6

Lopes, P.N., Brackett, M.A., Nezlek, J.B., Schütz, A., Sellin, I. \& Salovey, P. (2004) "Emotional intelligence and social interaction", Personality and Social Psychology Bulletin, vol. 30, no. 8: 1018-1034

Mandell, B. \& Pherwani, S. (2003) "Relationship between emotional intelligence and transformational leadership style: A gender comparison", Journal of Business and Psychology, vol. 17, no. 3: 387-404

Mayer, J.D. \& Salovey, P. (1997) “What is emotional intelligence?”, in Salovey, P. \& Sluyter, D.J. (eds.): Emotional development and E.I.: Educational implications, New York, NY: Basic Books

Mayer, J.D., Salovey, P., Caruso, D.R. \& Sitarenios, G. (2001) "Emotional intelligence as a standard intelligence", Emotion, vol. 3, no. 1: 232-242

Mayer, J.D. (2002) Mayer-Salovey-Caruso E.I. Test (MSCEIT), 2nd Edition, Toronto, Canada: Multi-Health Systems

Mayer, J.D., Salovey, P. \& Caruso, D.R. (2008) "Emotional intelligence: New ability or eclectic traits?", American Psychologist, vol. 63, no. 6: 503

Mayur, S.J., James, P.S. \& Swamynathan, R. (2015) "Emotional intelligence - A pathway to performance. A descriptive study among business administration graduates in Kerala”, Life Science Journal, vol. 12, no. 8, 88-93 
Mbacrystalball.com (2013) https://www.mbacrystalball.com/blog/2013/05/16/ average-age-for-mba-in-india-usa/. Accessed May 82019

McEnrue, M.P. \& Groves, K. (2006) "Choosing among tests of emotional intelligence: What is the evidence?", Human Resource Development Quarterly, vol. 17, no. 1: 9-42

Moon, S. (2011) East meets west: The cultural-relativity of emotional intelligence, $\mathrm{Ph}$. D Thesis, University of Toronto, Canada

Nelis, D., Quoidbach, J., Mikolajczak, M. \& Hansenne, M. (2009) "Increasing emotional intelligence:(How) is it possible?", Personality and Individual Differences, vol. 47, no. 1: 36-41

Nikolaou, I. \& Tsaousis, I. (2002) "Emotional intelligence in the workplace: Exploring its effects on occupational stress and organizational commitment", International Journal of Organizational Analysis, vol. 19, no. 4: 327-342

Nisbett, R. (2003) The geography of thought: How Asians and Westerners think differently ... and why, New York, NY: The Free Press, New York, NY

O'Boyle, E.H., Humphrey, R.H., Pollack, J.M., Hawver, T.H. \& Story, P.A. (2011) "The relation between emotional intelligence and job performance: A meta-analysis", Journal of Organizational Behavior, vol. 32, no. 5: $788-818$

OECD (2016) https://data.oecd.org/trade/trade-in-services.htm. Accessed May 8 2019

Oyserman, D., Coon, H.M. \& Kemmelmeier, M. (2000) "Rethinking individualism and collectivism: Evaluation of theoretical assumptions and meta-analyses", Psychological Bulletin, vol. 128, no. 1: 3-72

Pool, L.D. \& Qualter, P. (2012) "Improving emotional intelligence and emotional self-efficacy through a teaching intervention for university students", Learning and Individual Differences, vol. 22, no. 3: 306-312

Ranganathan, A. \& Kuruvilla, S. (2008) "Employee turnover in the business process outsourcing industry in India", in Management Practices in HighTech Environments, D. Jemielniak \& D. Kociatkiewicz (eds.). IGI Global: Hershey, PA, pp. 110-132

Rego, A., Sousa, F., Pina e Cunha, M., Correia, A. \& Saur-Amaral, I. (2007) "Leader self-reported emotional intelligence and perceived employee creativity: an exploratory study", Creativity and Innovation Management, vol. 16, no. 3: 250-264

Rodriguez, G., Lopez-Perez, B., Ferreo, M., Fernandez, E. \& Fernandez, J. (2017) "Impact of the Intensive Program of Emotional Intelligence (IPEI) on middle managers' emotional intelligence", Psicothema, vol. 29, no. 4: 508-13

Sigmar, L., Hynes, G.E. \& Cooper, T. (2010) "Emotional intelligence: pedagogical considerations for skills-based learning in business communication courses", Journal of Instructional Pedagogies, vol. 3: 1-11 
Singelis, T.M., Triandis, H.C., Bhawuk, D.P.S. \& Gelfand, M.J. (1995) "Horizontal and vertical dimensions of individualism and collectivism: A theoretical and measurement refinement", Cross-Cultural Research, vol. 29, no. 3: $240-275$

Shaikh, M. (2017) https://www.quora.com/How-many-employees-work-atDeloitte-US-India), Accessed May 42019

Stahl, G.K. \& Tung, R.L. (2015) "Towards a more balanced treatment of culture in international business studies: The need for positive cross-cultural scholarship", Journal of International Business Studies, vol. 46, no. 4: 391-414

Tang, H.W.V., Yin, M.S. \& Nelson, D.B. (2010) "The relationship between emotional intelligence and leadership practices: A cross-cultural study of academic leaders in Taiwan and the USA", Journal of Managerial Psychology, vol. 25, no. 8: 899-926

Van Rooy, D.L., Viswesvaran, C. \& Pluta, P. (2005) "An evaluation of construct validity: what is this thing called emotional intelligence?", Human Performance, vol. 18, no. 4: 445-462

Walter, F., Cole, M.S. \& Humphrey, R.H. (2011) "Emotional intelligence: Sine qua non of leadership or folderol?", The Academy of Management Perspectives, vol. 25 , no. 1: 45-59

Whitman, D.S., Van Rooy, D.L., Viswesvaran, C. \& Kraus, E. (2009) "Testing the second-order factor structure and measurement equivalence of the Wong and Law emotional intelligence scale across gender and ethnicity", Educational and Psychological Measurement, vol. 69, no. 6: 1059-1074

Wong, C.S. \& Law, K.S. (2002). "The effects of leader and follower emotional intelligence on performance and attitude: An exploratory study", The Leadership Quarterly, vol. 13, no. 3: 243-274

Yang, L., Brink, A.G. \& Wier, B. (2018) "The impact of emotional intelligence on auditor judgment", International Journal of Auditing, vol. 22, no. 1: 83-97

Zajonc, R.B. (1980) "Feeling and thinking: Preferences need no inferences", American Psychologist, vol. 35: 151-175 


\section{Appendix}

Examples of MSCEIT Question Types Provided by MHS

\section{Branch 1 Task}

Instructions: How much is each feeling below expressed by this face?

(Please select a response for each item.)

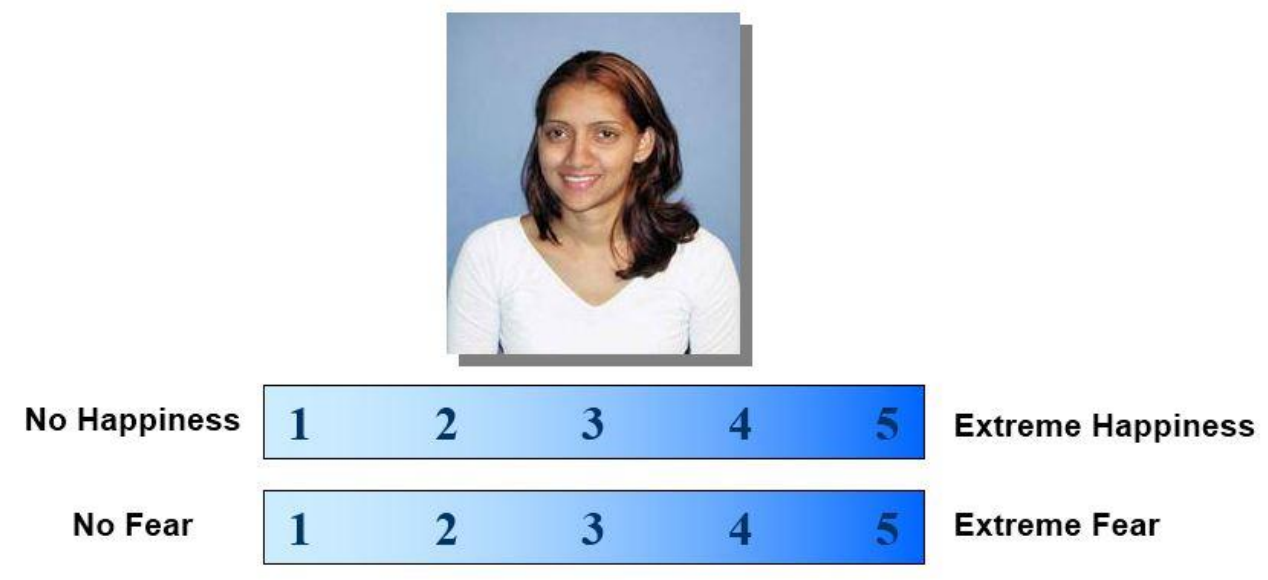




\section{Branch 2 Task}

What mood(s) might be helpful to feel when meeting in-laws for the very first time?

\begin{tabular}{|l|l|l|l|l|l|}
\hline & Not Useful & & & & Useful \\
\hline a. tension & 1 & 2 & 3 & 4 & 5 \\
\hline b. surprise & 1 & 2 & 3 & 4 & 5 \\
\hline c. joy & 1 & 2 & 3 & 4 & 5 \\
\hline
\end{tabular}

\section{Branch 3 Task}

Tom felt anxious and became a bit stressed when he thought about all the work he needed to do. When his supervisor brought him an additional project, he felt
a. overwhelmed
b. depressed
c. ashamed
d. self conscious
e. jittery

\section{Branch 4 Task}

Debbie just came back from vacation. She was feeling peaceful and content. How well would each action preserve her mood?

Action 1: She started to make a list of things she could do.

Action2: She started thinking about where and when she would go on her next vacation.

Action 3: She decided it was best to ignore the feeling since it wouldn.t last anyway.
a. Very ineffective
b. Somewhat ineffective
c. Neutral
d. Somewhat effective
e. Very effective 